\title{
Linhagens de coentro com pendoamento tardio sob dois sistemas de plantio
}

\author{
Gabriel M Maciel ${ }^{1}$; Cyro P Costa ${ }^{2}$; Fernando C Sala ${ }^{2}$ \\ ${ }^{1}$ Tecnoseed, Av. 21 de abril 1432, Centro, 98700-000 Ijuí-RS; desenvolvimento@tecnoseed.com.br; ${ }^{2}$ UFSCar-CCA, DBVPA; C. Postal \\ 153, 13600-970, Araras-SP; cpcosta@terra.com.br; fcsala@cca.ufscar.br
}

\begin{abstract}
RESUMO
O trabalho teve como objetivo avaliar o desempenho agronômico de linhagens de coentro tolerantes ao pendoamento precoce em dois sistemas de plantio (semeadura direta e transplante de mudas). $\mathrm{O}$ experimento foi conduzido de junho a novembro de 2010. Foram avaliadas três linhagens de coentro (Guarani\#1, Guarani\#21 e Guarani\#36), e a cultivar Verdão em delineamento experimental de blocos casualizados, com três repetições. Avaliou-se o número de folhas por planta (NF), massa verde do maço (MVM), rendimento de massa verde por $\mathrm{m}^{2}$ (REND), período comercial suportado no campo (COM), ciclo em dias (CIC) e percentagem de pendoamento (PP). A PP foi avaliada nos dois sistemas de plantio aos 20, 40, 60, 80, 100 e 120 dias após semeadura (DAS). Ocorreram diferenças significativas no sistema de plantio com mudas quanto ao NF, MVM e REND entre as linhagens Guarani\#36 e Guarani\#21 e 'Verdão'. A linhagem Guarani\#36 comparada com 'Verdão' foi superior nos parâmetros NF, MVM e REND em 246,05\%, 162,91\% e 165,38\%, respectivamente. Superioridade semelhante foi observada na linhagem Guarani\#21 com $211,95 \%, 148,10 \%$ e $150 \%$ para os parâmetros NF, MVM e REND, respectivamente. Não houve diferenças significativas para CIC entre as linhagens e 'Verdão'. No sistema de semeadura direta as linhagens Guarani\#36 e Guarani\#21 apresentaram efeitos significativos em todos os parâmetros avaliados quando comparadas com a cultivar Verdão, exceto para ciclo das linhagens. Nos parâmetros NF, MVM e REND a linhagem Guarani\#36 apresentou superioridade de $251,27 \%, 148,14 \%$ e $150 \%$ à cv. Verdão, respectivamente. Também superior, a linhagem Guarani\#21 comparada com 'Verdão' apresentou superioridades de $218,13 \%, 136,18 \%$ e $137,50 \%$ para NF, MVM e REND, respectivamente. As três linhagens foram superiores a 'Verdão' quanto ao COM para os dois sistemas de plantio. As linhagens Guarani\#21 e Guarani\#36 apresentam pendoamento mais tardio em ambos os sistemas de produção quando comparados com a cv. Verdão.
\end{abstract}

Palavras-chave: Coriandrum sativum, florescimento, sistema de produção.

\section{ABSTRACT \\ Coriander lines with later-bolting resistance under two planting systems}

The agronomic performance was evaluated on coriander lines tolerant to early bolting under two production systems (no-tillage and seedling transplant). The experiment was carried out from June to November 2010. Three coriander lines were evaluated (Guarani\#1, Guarani\#21 and Guarani\#36), and one control (cv. Verdão) in a randomized complete block experimental design, with three replications. The number of leaves per plant (NF), green mass (MVM), green mass $/ \mathrm{m}^{2}$ (REND), supported marketable period in the field (COM), cycle (CIC) and percentage of bolting (PP), were evaluated. The PP was evaluated in the two production systems at 20, 40, 60, 80, 100 and 120 days after sowing (DAS). Significant differences were obtained in the production system with seedling transplant for NF, MVM and DP between the lines Guarani\#36 and Guarani\#21 and 'Verdão'. The coriander line Guarani\#36 compared to the cv. Verdão was superior in NF, MVM and REND in $246.05 \%$, $162.90 \%$ and $165.38 \%$, respectively. Similar superiority was observed in the coriander line Guarani\#21 with $211.95 \%, 148.10 \%$ and $150.00 \%$ for parameters NF, MVM and REND, respectively. There were no significant differences for CIC between the lines and 'Verdão'. 'In the system of no-tillage the coriander lines Guarani\#36 and Guarani\#21 presented significant effect in all the evaluated parameters when compared to cv. Verdão, except for cycle of the coriander lines. In the parameters NF, MVM and REND the Guarani\#36 coriander line presented superiority of $251.27 \%, 148.14 \%$ and $150 \%$ to the $\mathrm{cv}$. Verdão, respectively. The Guarani\#21 coriander line compared to cv. Verdão presented superiority of $218.13 \%, 136.17 \%$ and $137.50 \%$ for NF, MVM and REND, respectively. The three lines were superior to cv. Verdão on COM for the two tillage systems. The coriander lines Guarani\#21 and Guarani\#36 present later-bolting in both the systems of production when compared to the cv. Verdão.

Keywords: Coriandrum sativum, bolting, no-tillage system.

(Recebido para publicação em 27 de outubro de 2011; aceito em 28 de agosto de 2012) (Received on October 27, 2011; accepted on August 28, 2012)

$\mathrm{O}$ coentro (Coriandrum sativum) é uma hortaliça herbácea anual pertencente à família Apiaceae. Devido à versatilidade de uso, é uma olerácea de considerável valor e de grande importância sócio-econômica (Diederichsen, 1996).

No Brasil, tem sido cultivado por pequenos e médios produtores, tanto para a produção de massa verde, comerciali- zada em feiras livres e supermercados, como também para a produção de frutos, utilizado nas indústrias alimentícias e cosméticas (Oliveira et al., 2005). Estima-se que a área cultivada com essa espécie no Brasil foi de 47.733 ha em 2011 (ABCSEM, 2011).

A cultivar Verdão é considerada líder de mercado em todo o Brasil (ABCSEM, 2011). É bastante vigorosa, com folhas de coloração verde-escura, excelente rusticidade e boa resistência às doenças de folhagens (Hortivale, 2007). Um dos grandes problemas enfrentados pelos produtores tem sido com o pendoamento precoce e, consequentemente, perda do produto olerícola. Avaliando seis genótipos de coentro, sendo duas cultivares comerciais (Verdão e Palmeira) e quatro linhagens (HTV 7299, HTV 
0999, HTV 0699 e HTV 9299) Oliveira et al. (2007) identificaram altas taxas de florescimento precoce aos 42 dias após a semeadura (apresentaram 65; 58; 35; 29; 40 e 59\% respectivamente).

O florescimento precoce interfere diretamente na comercialização e aceitação do produto nas gôndolas dos supermercados. Genótipos de coentro com longo período vegetativo, isto é, com pendoamento tardio seriam os mais indicados para plantios comerciais.

Recentemente alguns programas regionais de avaliação de genótipos de coentro foram realizados (Melo et al., 2009) porém, não se identificaram linhagens superiores no quesito produção de massa verde $/ \mathrm{m}^{2}$ e pendoamento lento em relação às cultivares comerciais.

A identificação de cultivares adaptadas com maior potencial produtivo proporciona maior segurança aos produtores, sendo ainda uma informação que poderá facilitar a obtenção de crédito e aceitação do produto no mercado consumidor (Hamasaki et al., 1998).

São poucas as pesquisas realizadas no Brasil com o coentro, que incluam tecnologia adequada no sistema de produção e desenvolvimento de novas cultivares (Pereira et al., 2005). Atualmente, pela falta de opção de genótipos superiores aliada à escassez de pesquisas voltadas para o melhoramento genético do coentro no Brasil, estão sendo utilizadas as cultivares disponíveis nas diversas regiões geográficas, sem se considerar as suas possíveis diferenças de comportamento nos diversos ambientes (Wanderley Júnior \& Melo, 2003).

Torna-se importante a condução de trabalhos de melhoramento para o desenvolvimento de novas cultivares de coentro e, concomitantemente, realizar estudos comparativos do comportamento desses genótipos em diferentes ambientes de cultivo. Esses estudos constituem importante ferramenta a ser utilizada na recomendação de cultivares e fornecem subsídios para novos programas de melhoramento genético. Também, a identificação de genótipos estáveis, que possam ser utilizados em diferentes zonas de cultivo e épocas de plantio, é interessante para produtores e empresas do setor de sementes (Alvarez \& Curioni, 1993; Peixoto et al., 1993).
O cultivo do coentro no Brasil tem sido realizado, preferencialmente por semeadura direta, utilizando grandes quantidades de sementes devido ao seu baixo valor no mercado. Em algumas regiões, os produtores dividem os frutos, obtendo sementes partidas, para maior rendimento de semeadura e, em determinados casos, para obter melhoria na germinação (Nascimento et al., 2006). A produção de mudas dessa espécie, apesar de ser uma alternativa para minimizar possíveis problemas com baixa germinação, emergência irregular e "stand" desuniforme em cultivo no campo, na hidroponia tem sido amplamente utilizada. Entretanto, não existem trabalhos, na literatura, comparando a eficiência do sistema de semeadura direta em relação ao de produção de mudas de coentro para cultivo em campo.

Objetivou-se avaliar o desempenho agronômico de três linhagens de coentro, visando boas características agronômicas aliadas ao pendoamento lento sob dois sistemas de plantio, utilizando a cultivar comercial Verdão como testemunha referencial.

\section{MATERIAL E MÉTODOS}

O experimento foi conduzido de junho a novembro de 2010, na Estação de Pesquisa e Desenvolvimento de Hortaliças da empresa Tecnoseed, localizada em Bozano-RS (28'23'16'S, $53^{\circ} 54^{\prime} 53^{\prime \prime} \mathrm{O}$, altitude de $328 \mathrm{~m}$ ). O clima é classificado segundo o sistema Köppen, como Cfa, isto é, subtropical úmido, sem estiagem típica. A temperatura média $\left({ }^{\circ} \mathrm{C}\right)$, a precipitação pluviométrica ( $\mathrm{mm})$ e a umidade relativa $(\%)$ no período de execução do experimento foram respectivamente: junho $=16,2$; 137,$6 ; 92$, julho $=15,9 ; 102,8,90$, agosto $=18,2 ; 86,2 ; 87,1$, setembro $=25,4$; 74,$4 ; 86$, outubro $=24,5 ; 58,7 ; 4 ; 82 \mathrm{e}$ novembro $=26,5 ; 37,4 ; 87,8$.

O solo utilizado apresentou as seguintes características químicas e físicas: $\mathrm{pH}\left(\mathrm{H}_{2} \mathrm{O}\right)=6,0 ; \mathrm{P}$ disponível $=5,0$ $\mathrm{mg} \mathrm{dm}{ }^{-3} ; \mathrm{K}=352,0 \mathrm{mg} \mathrm{dm}^{-3} ; \mathrm{Ca}^{+2}=$

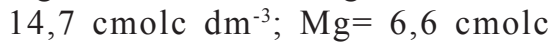
$\mathrm{dm}^{-3} ; \mathrm{H}+\mathrm{Al}$ trocável $=7,7 \mathrm{cmolc} \mathrm{dm}^{-3}$; matéria orgânica $=3,7 \mathrm{~kg} \mathrm{dm}^{-3}$; Argila $(\%)=30$; Índice $\mathrm{SMP}=5,5$; Alumínio = 0,1 cmolc dm $^{-3} ;$ CTC $_{\mathrm{pH} 7,0}=29,9$ cmolc $\mathrm{dm}^{-3}$; Sat CTC ${ }_{\mathrm{pH} 7,0}$ por bases $=74,1 \%$; Sat $\mathrm{CTC}_{\text {efetiva }}$ por alumínio $=0,4$; Cobre $=8,1 \mathrm{mg} \mathrm{dm}^{-3} ;$ Zinco $=6,4 \mathrm{mg} \mathrm{dm}^{-3} \mathrm{e}$ Manganês $=37,3 \mathrm{mg} \mathrm{dm}^{-3}$.

Foram avaliadas três linhagens de coentro (Guarani\#1, Guarani\#21 e Guarani\#36), e a cultivar Verdão sob dois sistemas de plantio (semeadura direta e plantio com mudas) em delineamento experimental de blocos casualizados, com três repetições. As linhagens Guarani\#1, Guarani\#21 e Guarani\#36 foram obtidas após hibridação entre os acessos TE6 e TE10 seguido de cinco ciclos de endogamia e pertencentes ao programa de melhoramento de coentro da empresa Tecnoseed. As linhagens foram avançadas por autofecundação até a geração S4 (S0-S4). A seleção de plantas para pendoamento tardio foi feita pelo método genealógico.

As parcelas mediram 4,0 $\mathrm{m}^{2}(1,0$ $\mathrm{m}$ de largura $\mathrm{x}$ 4,0 $\mathrm{m}$ de comprimento) contendo 200 plantas nos dois sistemas de cultivo, sendo todas consideradas úteis. $\mathrm{O}$ espaçamento adotado foi $0,1 \mathrm{~m}$ (planta) e 0,2 m (linha).

A adubação constou da aplicação de $5,0 \mathrm{~kg} \mathrm{~m}^{-2}$ de esterco bovino curtido e seco, 10,0 $\mathrm{g} \mathrm{m}^{-2}$ de cloreto de potássio e de $60 \mathrm{~g} \mathrm{~m}^{-2}$ de superfosfato simples, aplicadas sete dias antes da semeadura, e de $25 \mathrm{~g} \mathrm{~m}^{-2}$ de nitrato de cálcio, fornecido em adubação de cobertura, parcelado $50 \%$ aos 20 e $50 \%$ aos 40 dias após a semeadura (DAS). Foram realizadas aplicações quinzenais do adubo foliar NIPHOKAM $^{\circledR} 108$ na dosagem de 1,0 $\mathrm{mL} \mathrm{L}^{-1}$ de água.

O preparo do solo, tanto para o sistema de transplantio de mudas quanto para o sistema de semeadura direta, constou da confecção de canteiros com rotoencanteirador.

O semeio para obtenção das mudas (sistema de produção com mudas) foi realizado no mesmo dia da semeadura direta (01/06/2010). As mudas foram produzidas em bandejas de poliestireno com 200 células utilizando substrato Tecnomax $^{\circledR}$. Decorridos 17 DAS foi realizado o desbaste deixando uma muda por célula. O transplantio foi realizado aos 25 dias após semeadura completando as parcelas na área experimental. Utilizou-se bordadura em toda área experimental. 
A semeadura direta constou da distribuição das sementes em sulcos longitudinais, de maneira manual, realizando-se o desbaste vinte dias depois, deixando-se uma planta.

Durante a execução do experimento realizaram-se os tratos culturais conforme preconizados para a cultura (Filgueira, 2003), incluindo irrigação por aspersão nos períodos de ausência de precipitações, em que todos os genótipos receberam a mesma lâmina de água, e capinas manuais.

Foi avaliado o número de folhas por planta (NF) (coleta de 20 amostras (plantas) por repetição e contagem); Obteve-se valores médios para cada repetição antes de analisar estatisticamente; massa verde do maço (MVM) (avaliada aos 49 dias (DAS) correspondendo ao peso (g) de talos e folhas de 100 plantas de cada parcela); rendimento de massa verde por $\mathrm{m}^{2}$ (REND) (estimativa da produção por $\mathrm{m}^{2}$ a partir dos valores obtidos do MVM); período comercial suportado no campo (COM) (obtido entre o início do ponto comercial até o último dia antes do pendoamento; considerou-se início do pendoamento quando as plantas iniciavam o crescimento da haste principal tornando o maço não-comercializável); ciclo em dias (CIC) (considerado entre o semeio e o início do ponto comercial) nos quatro genótipos de coentro sob dois sistemas de plantio e percentagem de pendoamento (PP) (foram observadas 100 plantas nas parcelas) aos 20,40, 60, 80, 100, 120 dias (DAS).

Para o cálculo do REND, conhecendo o espaçamento padrão adotado, foi empregada a fórmula REND $(\mathrm{kg})=$ (MVM/100 plantas) x 200 plantas $\mathrm{m}^{-2}$.

Os dados foram submetidos às análises de variância, sendo os qua- drados médios comparados pelo teste F (5\%). Para comparação das médias da NF, MVM, REND, COM e CIC, foi empregado o teste Scott-Knott, a 5\% de probabilidade, enquanto as médias do PP foram submetidas a análises de regressão. Foram realizados ainda contrastes ortogonais comparando os dois métodos de plantio. Os dados foram avaliados por meio do programa estatístico SISVAR, versão 4.3 (Ferreira, 2002). Os efeitos referentes à percentagem de pendoamento, quando significativos pelo teste $\mathrm{F}$ na análise de variância, foram submetidos à análise de regressão, tendo sido empregados polinômios ortogonais.

\section{RESULTADOS E DISCUSSÃo}

Houve efeito significativo dos genótipos $(\mathrm{p}<0,05)$ para número de folhas por planta (NF), massa verde do maço

Tabela 1. Número de folhas por planta (NF), massa verde do maço (MVM), rendimento de massa verde por $\mathrm{m}^{2}$ (REND), período comercial suportado no campo (COM), ciclo em dias (CIC) de linhagens de coentro sob dois sistemas de plantio (leaf number/plant (NF), green mass (MVM), green mass $\mathrm{m}^{2}$ (REND), supported marketable period in the field (COM), cycle (CIC) and percentage of bolting (PP) of the coriander lines tolerant to early bolting under two planting systems. Bozano, Tecnoseed, 2010.

\begin{tabular}{|c|c|c|c|c|c|}
\hline \multirow{2}{*}{ Cultivares } & \multicolumn{5}{|c|}{ Mudas $^{x}$} \\
\hline & NF & MVM (g) & REND $\left(\mathrm{kg} \mathrm{m}^{-2}\right)$ & COM (dias) & CIC (dias) \\
\hline T1 $\quad$ Verdão & $39,3 \mathrm{c}$ & $79,0 \mathrm{~b}$ & $2,6 b$ & $2,3 d$ & $51,0 \mathrm{a}$ \\
\hline T2 Guarani \#1 & $38,0 \mathrm{c}$ & $75,0 \mathrm{~b}$ & $2,4 b$ & $21,3 b$ & $57,3 \mathrm{a}$ \\
\hline T3 Guarani \#21 & $83,3 \mathrm{~b}$ & $117,0 \mathrm{a}$ & $3,9 \mathrm{a}$ & $27,7 \mathrm{a}$ & $56,0 \mathrm{a}$ \\
\hline \multirow{2}{*}{$\begin{array}{ll}\text { T4 Guarani \#36 } \\
\\
\text { Média Geral }\end{array}$} & $96,7 \mathrm{a}$ & $128,7 \mathrm{a}$ & $4,3 \mathrm{a}$ & $12,3 \mathrm{c}$ & $51,0 \mathrm{a}$ \\
\hline & 64,3 & 99,9 & 3,3 & 15,9 & 54,0 \\
\hline CV (\%) & 7,1 & 7,7 & 7,7 & 18,1 & 7,8 \\
\hline \multirow{2}{*}{ Cultivares } & \multicolumn{5}{|c|}{ Direto $^{x}$} \\
\hline & NF & MVM (g) & REND $\left(\mathrm{kg} \mathrm{m}^{-2}\right)$ & COM (dias) & CIC (dias) \\
\hline $\begin{array}{ll}\text { T5 } & \text { Verdão }\end{array}$ & $35,3 \mathrm{c}$ & $72,7 b$ & $2,4 b$ & $1,6 \mathrm{~d}$ & $45,7 \mathrm{a}$ \\
\hline T6 Guarani \#1 & $33,3 \mathrm{c}$ & $70,0 \mathrm{~b}$ & $2,3 b$ & $17,3 b$ & $49,7 \mathrm{a}$ \\
\hline T7 Guarani \#21 & $77,0 \mathrm{~b}$ & $99,0 \mathrm{a}$ & $3,3 \mathrm{a}$ & $23,0 \mathrm{a}$ & $51,0 \mathrm{a}$ \\
\hline \multirow{2}{*}{$\begin{array}{ll}\text { T8 } & \text { Guarani } 36 \\
& \text { Média Geral }\end{array}$} & $88,7 \mathrm{a}$ & $107,7 \mathrm{a}$ & $3,6 \mathrm{a}$ & $10,6 \mathrm{c}$ & $51,0 \mathrm{a}$ \\
\hline & 58,6 & 87,3 & 2,9 & 13,2 & 49,3 \\
\hline $\mathrm{CV}(\%)$ & 7,5 & 8,4 & 8,2 & 20,7 & 7,4 \\
\hline \multirow{2}{*}{ Contrastes de interesse } & \multicolumn{5}{|c|}{ Estimativas dos contrastes (y) } \\
\hline & NF & MVM (g) & REND $\left(\mathrm{kg} \mathrm{m}^{-2}\right)$ & COM (dias) & CIC (dias) \\
\hline $\mathrm{C} 1 \quad[(\mathrm{~T} 1+\mathrm{T} 2+\mathrm{T} 3+\mathrm{T} 4) / 4-(\mathrm{T} 5+\mathrm{T} 6+\mathrm{T} 7+\mathrm{T} 8) / 4]$ & $5,75^{\mathrm{ns}}$ & $12,58^{\text {ns }}$ & $0,41^{\text {ns }}$ & $2,75^{\mathrm{ns}}$ & $4,66^{\mathrm{ns}}$ \\
\hline $\mathrm{C} 2 \quad[(\mathrm{~T} 2+\mathrm{T} 3+\mathrm{T} 4) / 3-(\mathrm{T} 1)]$ & $33,33 * *$ & $27,88^{*}$ & $0,93 *$ & $18,11^{* *}$ & $3,11^{\mathrm{ns}}$ \\
\hline $\mathrm{C} 3 \quad[(\mathrm{~T} 6+\mathrm{T} 7+\mathrm{T} 8) / 3-(\mathrm{T} 5)]$ & $31,00 * *$ & $19,55^{\mathrm{ns}}$ & $0,65^{\text {ns }}$ & $15,33 * *$ & $4,88^{\text {ns }}$ \\
\hline $\mathrm{C} 4 \quad[(\mathrm{~T} 2+\mathrm{T} 3+\mathrm{T} 4) / 3-(\mathrm{T} 6+\mathrm{T} 7+\mathrm{T} 8) / 3]$ & $6,33^{\mathrm{ns}}$ & $14,66^{\mathrm{ns}}$ & $0,48 * *$ & $3,44^{\text {ns }}$ & $4,22^{\mathrm{ns}}$ \\
\hline
\end{tabular}

${ }^{\mathrm{x}}$ Médias seguidas da mesma letra nas colunas não diferem entre si pelo teste de Scott-Knott ao nível de $5 \%$ de probabilidade ( $\left.\mathrm{p}=0.05\right)$ [ ${ }^{\mathrm{x}}$ means followed by the same letter within the columns do not differ from each other by Scott-Knott multiple range test ( $\left.\left.\mathrm{p}=0.05\right)\right] ;(\mathrm{y}) * *$, *, ns $=$ significativo $\mathrm{p}=0.01, \mathrm{p}=0.05$ e não significativo, respectivamente, pelo teste Scheffé $[(\mathrm{y}) * *, *, \mathrm{~ns}=$ significant $\mathrm{p}=0.01, \mathrm{p}=0.05$ and not significant, respectively, for the Scheffé test]. 


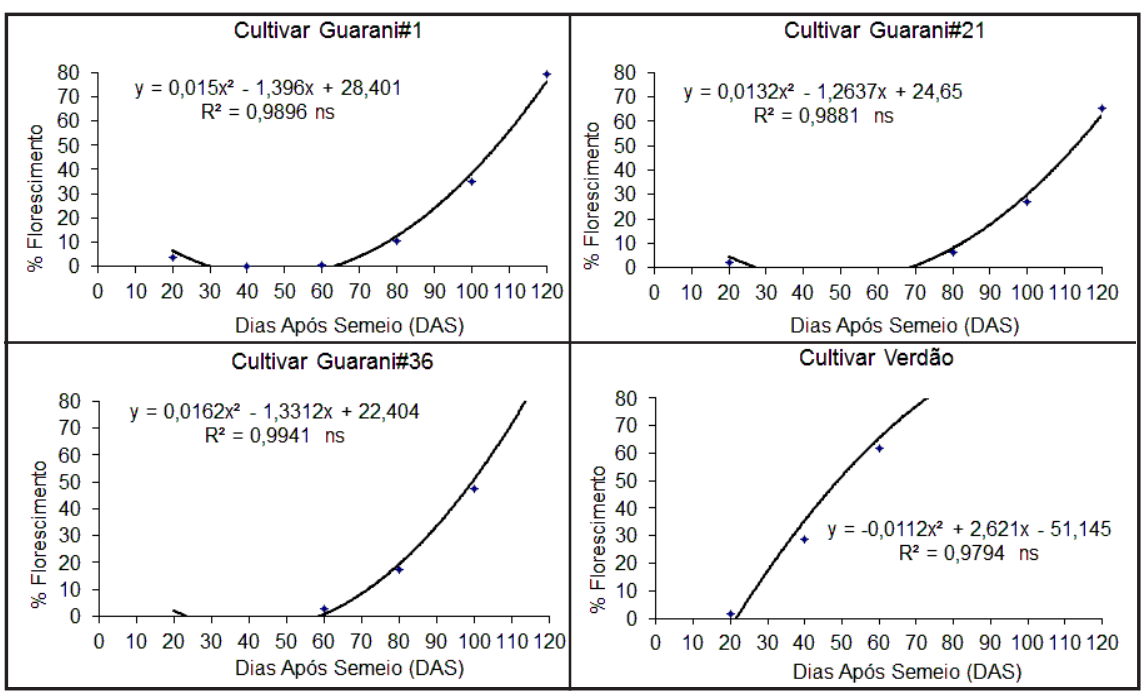

Figura 1. Florescimento (\%) de quatro linhagens de coentro no decorrer do ciclo (DAS) sob o sistema de plantio por mudas [bolting (\%) of four coriander lines in days after sowing under the seedling transplanting system]. Bozano, Tecnoseed, 2010.

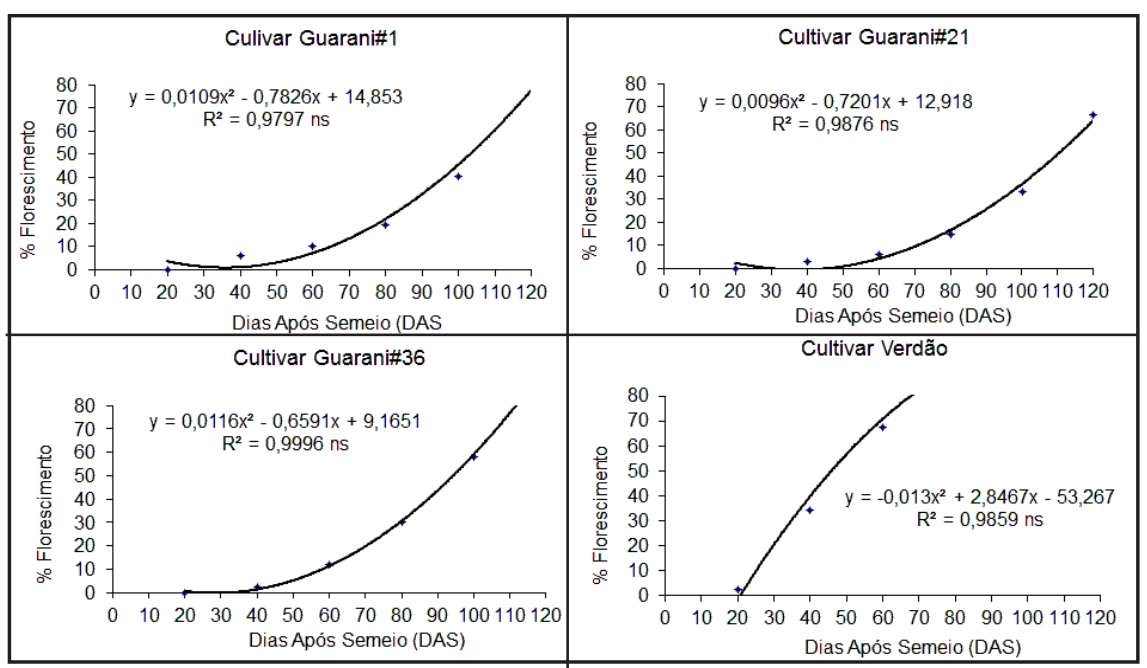

Figura 2. Florescimento (\%) de quatro linhagens de coentro no decorrer do ciclo (DAS) sob o sistema de plantio direto [bolting ( $\%)$ of four coriander lines in days after sowing under the production no-tillage system]. Bozano, Tecnoseed, 2010.

(MVM), rendimento de massa verde por $\mathrm{m}^{2}$ (REND), período comercial suportado no campo (COM) tanto no sistema de produção por mudas quanto no sistema de semeadura direta (Tabela 1).

No sistema de produção com mudas destacaram-se as linhagens Guarani\#21 e Guarani\#36, com efeitos significativos para todos os parâmetros avaliados quando comparados com a cv. Verdão, exceto o ciclo das linhagens.

A linhagem Guarani\#36 comparada com a cv. Verdão foi superior nos parâmetros NF, MVM e REND em 246,05\%, $162,91 \%$ e $165,38 \%$, respectivamente. Superioridade semelhante foi observada na linhagem Guarani\#21 com 211,96\%, $148,10 \%$ e $150 \%$ para os parâmetros NF, MVM e REND, respectivamente. Nas condições de Passo Fundo-RS, Marques \& Lorencetti (1999), verificaram rendimento de $2,4 \mathrm{~kg} \mathrm{~m}^{-2}$ para a cultivar Verdão.

Atualmente, e já por um longo período, a cultivar Verdão vem sendo cultivada pela maioria dos produtores (Hortivale, 2007; ABCSEM, 2011) em várias regiões. Estudos demonstraram a carência de novas cultivares que apresentem superioridade quanto ao comportamento agronômico e tolerância ao pendoamento precoce, quando comparadas à cultivar Verdão (Oliveira et al., 2007).

Estudo de progênies de meios-irmãos da cultivar Verdão para características agronômicas foi realizado por Melo et al. (2009) onde constataram-se valores médios e altos de herdabilidade no sentido amplo e forte correlação genotípica entre algumas características, possibilitando ganhos genéticos. Porém estes genótipos ainda não se encontram disponíveis para plantios comerciais.

No sistema de semeadura direta as linhagens Guarani\#36 e Guarani\#21 apresentaram efeitos significativos em todos os parâmetros avaliados quando comparadas com a cultivar Verdão, exceto para ciclo (CIC). Nos parâmetros NF, MVM e REND a linhagem Guarani\#36 apresentou superioridade de $251,27 \%, 148,14 \%$ e $150 \%$ à $\mathrm{cv}$. Verdão, respectivamente. A linhagem Guarani\#21 apresentou superioridade de $218,13 \%, 136,18 \%$ e $137,50 \%$ para NF, MVM e REND, respectivamente, quando comparada à 'Verdão'. De maneira similar ao plantio com mudas, as linhagens Guarani\#36 e Guarani\#21 foram superiores apresentando maços vigorosos, destacando-se nas parcelas. Fato este confirmado pelas diferenças significativas encontradas neste experimento (Tabela 1).

Quanto aos sistemas de plantio não houve diferenças significativas (Tabela 1). Estes efeitos podem ser observados no contraste $\mathrm{C} 1$. Os resultados obtidos no $\mathrm{C} 1$ permitem que o produtor escolha entre os sistemas de plantio com mudas ou semeadura direta, qual sistema é mais viável na sua propriedade para as linhagens avaliadas. Pelo contraste $\mathrm{C} 2$ pode-se observar a superioridade agronômica das três linhagens (Guarani\#1, Guarani\#21 e Guarani\#36) quando comparadas com a cultivar Verdão no sistema de plantio por mudas. Valores significativos (1 e 5\%) foram obtidos para NF. Foram encontradas 33,33 folhas a mais que na cultivar Verdão. O MVM obtido foi de $27,88 \mathrm{~g}$ (significativo a $5 \%$ de probabilidade). Outro parâmetro que se diferenciou significativamente a $5 \%$ de probabilidade foi REND. O comportamento agronômico das três linhagens proporcionou uma diferença de $930,0 \mathrm{~g}$ a mais no REND se comparada à culti- 
var Verdão (C2). Esta superioridade, se estimada para a produção em um hectare de coentro, equivaleria a uma produção de 9,3 t a mais em relação à cultivar Verdão. No entanto, sugerem-se outras avaliações agronômicas visando identificar melhor espaçamento entre outras características, objetivando melhoria no desempenho destas linhagens.

Quanto ao período compreendido entre o início do ponto comercial até o último dia antes do pendoamento (COM) ocorreram efeitos significativos a 1 e $5 \%$ de probabilidade. As três linhagens estenderam o período comercial (COM) para 18,11 dias a mais em relação à cultivar Verdão. A capacidade de essas linhagens se manterem a campo sem ocorrer pendoamento precoce é de fundamental importância para os produtores dessa folhosa. Maior amplitude, em dias, entre o início do ponto comercial até o início do pendoamento permite ao produtor maior flexibilidade de venda além de facilitar a logística diminuindo desperdícios e prejuízo.

No sistema de semeadura direta (C3) não ocorreram efeitos significativos para MVM, REND e CIC. Efeitos significativos foram obtidos no NF (31 folhas a mais) e no COM (15,33 dias). Independente do sistema de plantio com mudas ou semeio direto, os valores obtidos do COM indicam que as linhagens Guarani\#1, Guarani\#21 e Guarani\#36 são tolerantes ao pendoamento precoce.

Quanto à comparação do desempenho das linhagens Guarani\#1, Guarani\#21 e Guarani\#36 nos dois sistemas de plantio, ocorreram efeitos significativos (1 e 5\% de probabilidade) para REND (C4). Nestas linhagens o melhor sistema de plantio foi com mudas permitindo ganhos de $0,480 \mathrm{~kg} \mathrm{~m}^{-2}$. Recomendam-se avaliações futuras dando continuidade ao desenvolvimento destas linhagens quanto ao sistema de produção.

Em relação à percentagem de pendoamento precoce, no sistema de plantio por mudas (Figura 1), na linhagem Guarani\#1, observou-se ocorrência de plantas pendoadas a partir dos 60 DAS. Na linhagem Guarani\#21, o início do pendoamento ocorreu aproximadamente aos 70 DAS, porém de forma mais lenta. Aos 100 DAS ocorreu pendoamento de até $30 \%$ e aos 120
DAS as plantas não se apresentaram 100\% pendoadas demonstrando maior tolerância ao pendoamento precoce. A cultivar Guarani\#21 apresentou maior resistência ao pendoamento. A linhagem Guarani\#36 iniciou o pendoamento aos 60 DAS de maneira similar à linhagem Guarani\#1 sendo que ambas apresentaram maior percentagem de pendoamento que a Guarani\#21. $\mathrm{O}$ percentual de plantas pendoadas na cultivar Verdão foi considerado muito elevado quando comparado com o das três linhagens. O coentro Verdão iniciou o pendoamento de maneira muito precoce (aproximadamente aos 22 DAS). O pendoamento ocorreu de forma rápida sendo que aos 120 DAS $100 \%$ das plantas já estavam pendoadas.

No sistema de semeadura direta (Figura 2) foi observada maior taxa de pendoamento em todas as linhagens avaliadas quando comparada ao pendoamento das linhagens no sistema com mudas. A linhagem Guarani\#1 iniciou o pendoamento aos 40 DAS e apresentou 100\% de plantas pendoadas aos 120 DAS. A linhagem Guarani\#21 manteve a superioridade apresentando comportamento similar em ambos os sistemas de produção. Ela teve inicio do pendoamento aproximadamente aos 50 DAS. Vale ressaltar que, mesmo aos $120 \mathrm{DAS}$, as plantas ainda não tinham alcançado $100 \%$ de pendoamento. O pendoamento das plantas da linhagem Guarani\#36 foi iniciado aos 40 DAS sendo que aos 120 DAS as plantas apresentaram-se 100\% pendoadas. Semelhante ao plantio com mudas, a cultivar Verdão apresentou pendoamento muito precoce. Iniciou aos 20 DAS e aos 100 DAS as plantas apresentaram-se $100 \%$ pendoadas.

Observando as Figuras 1 e 2, aos 42 dias, mesma data avaliada por Oliveira et al. (2007), as linhagens Guarani\#1, Guarani\#21 e Guarani\#36 apresentaram apenas o início do estádio fenológico de florescimento.

Percebe-se pelos resultados a superioridade das linhagens Guarani\#21 e Guarani\#36 para cultivo visando obtenção de maços. Estas duas linhagens apresentam boas características agronômicas aliadas ao pendoamento tardio permitindo aos produtores maior período de colheita durante o cultivo desses dois materiais. Novas técnicas de cultivo devem ser avaliadas visando avanços no sistema de produção destas linhagens.

\section{AGRADECIMENTOS}

À empresa Tecnoseed pela infra-estrutura.

\section{REFERÊNCIAS}

ABCSEM. www.abcsem.com.br. Acesso em 24/01/2012.

ALVAREZ A; CURIONI A. 1993. Efecto de dos épocas de siembra sobre el rendimiento y la producción de biomassa en coriandro (Coriandrum sativum L.). Anales SAIPA 11: 211-215.

DIEDERICHSEN A. 1996. Coriander (Coriandrum sativum L.) promoting the conservation and use of underutilized and negleted crops. 3. Rome: Institute of Plant Genetics and Crop Plant Research, Gatersleben/International Plant Genetic Resources Institute. 83 p.

FERREIRA DF. 2002. SISVAR. Sistemas de análises de variância para dados balanceados: programa de análises estatísticas e planejamento de experimentos. Versão 4.3. Lavras: UFLA.

FILGUEIRA FAR. 2003. Novo manual de olericultura: agrotecnologia moderna na produção e comercialização de hortaliças. Viçosa: UFV. 412 p.

HAMASAKI RI; BRAZ LT; PURQUERIO LFV; PEIXOTO N. 1998. Comportamento de novas cultivares de feijão-vagem em JaboticabalSP. In: CONGRESSO BRASILEIRO DE OLERICULTURA, 38. Resumos... Petrolina: SOB (CD-ROM).

HORTIVALE. 2007. Hortivale-Sementes do Vale Ltda. Disponível em http://www.hortivale. com.br/

MARQUES FC; LORENCETTI BL. 1999. Avaliação de três cultivares de coentro (Coriandrum sativum L.) semeadas em duas épocas. Pesquisa Agropecuária Gaúcha 5: 265-270.

MELO RA; MENEZES D; RESENDE LV; WANDERLEY JÚNIOR LJG; SANTOS VF; MESQUITA JCP; MAGALHÃES AG. 2009. Variabilidade genética em progênies de meiosirmãos de coentro. Horticultura Brasileira 27: 325-329.

NASCIMENTO WM; PEREIRA RS; FREITAS RA; BLUMER L; MUNIZ MFB. 2006. Colheita e armazenamento de sementes de coentro. Pesquisa Agropecuária Brasileira 41: 1793-1801.

OLIVEIRA AP; MELO PCT; WANDERLEY JÚNIOR LJG; ALVES AU; MORA MF; OLIVEIRA ANP. 2007. Desempenho de genótipos de coentro em Areia. Horticultura 
Brasileira 25: 252-255.

OLIVEIRA EQ; BEZERRA NETO FB; NEGREIROS MZ; BARROS JÚNIOR AP; FREITAS KKC; SILVEIRA LM; LIMA JSS. 2005. Produção e valor agroeconômico no consórcio entre cultivares de coentro e de alface. Horticultura Brasileira 23: 285289.
PEIXOTO N; SILVA LO; THUNG MDT; SANTOS G. 1993. Produção de sementes de linhagens e cultivares arbustivas de feijãovagem em Anápolis. Horticultura Brasileira 11: 151-152.

PEREIRA RS; MUNIZ MFB; NASCIMENTO WM. 2005. Aspectos relacionados à qualidade de sementes de coentro. Horticultura Brasileira 23: 703-706.

WANDERLEY JÚNIOR LJG; MELO PCT. 2003. Tapacurá: nova cultivar de coentro adaptada às condições subtropicais do Brasil. In: CONGRESSO BRASILEIRO DE OLERICULTURA, 43. Resumos... Recife: SOB (CD-ROM). 